\title{
Developing Volunteer Leaders: Let Their Intentions Guide the Way
}

\author{
Janina M. Fuller, Ph.D. \\ Curtis R. Friedel, Ph.D. \\ Assistant Professor \\ Director of the Center for Cooperative Problem Solving \\ Virginia Tech.
}

\begin{abstract}
As more citizens choose to volunteer in local and national groups, volunteer organizations and leadership educators have recognized a need to identify who has intentions to develop their leadership as a volunteer. By identifying these intentions, leadership educators may more accurately target those individuals who would like to develop their leadership in a particular organization. For this purpose, the Volunteer Leadership Development Questionnaire (VLDQ) was developed using the theory of planned behavior to guide the collection of qualitative and quantitative data. This pilot study provides evidence the VLDQ may accurately measure an individual's intentions to develop their leadership as a volunteer.
\end{abstract}

\section{Introduction}

More than one quarter of the U.S. adult population participates in some form of volunteer service (Corporation for National and Community Service, 2013). As the nation grapples with continued economic challenges, its citizens are being called upon to play a more active role than ever before, and to take on increasing levels of accountability in the interest of enabling programs to function in the face of budgetary pressures. While our understanding of volunteer motivation and behavior has vastly increased in the past 20 years, there remains much tolearn about how to empower volunteers in developing and expressing the degree of leadership that is required by many volunteer organizations providing services to those less fortunate.

Volunteers who donate their time and energy in the interest of helping others gain knowledge, skills and insights that contribute to their personal growth and development, while expanding the possibilities for caring and collaboration throughout whole communities. Many of these volunteers demonstrate the attributes of leadership, but how do we know if they intend to further develop their leadership?

Many theories have been used to distinguish various aspects of leadership. Regardless of the conceptual underpinnings of a given leadership theory, however, the quality and character of leadership are specific to the context in which it is observed. Volunteer administration professionals have noted the lack of empirical evidence supporting development of theoretically based volunteer curricula and training programs (Connors \& Swan, 2006; Stedman, 2004). A reliable methodology for ascertaining volunteers' leadership attitudes and intentions is needed to enhance support of those who volunteer to improve their communities (Snyder \& Omoto, 2008). 
With these facts in mind, and in collaboration with the HandsOn Network (HON), we conducted research to develop an instrument, the Volunteer Leadership Development Questionnaire (VLDQ), with which to discover the factors influencing volunteers' intentions to develop their leadership. We used the Theory of Planned Behavior (TPB) as the theoretical framework for guiding our research; which states that attitudes, subjective norms and perceived behavioral control all influence intentionality, and indirect measures of behavioral, normative and control beliefs are associated with their respective direct measures (Ajzen, 1991, 2005). If TPB is suitable for best identifying a volunteer's intention to develop leadership, leadership educators may be more efficient in selecting and developing the leadership of volunteers.

Background of the Study. Recognizing the need for leadership educators to utilize volunteers for building viable communities able to solve complex problems in the future (Andenoro, et al, 2013), much is yet to be understood about how volunteers develop as leaders. Further, the work of leadership educators with Cooperative Extension personnel (e.g. administrators, specialists, and county agents) requires a basic understanding of how volunteers develop their leadership, within the context of serving as a volunteer. Note, this characterization of leadership development of volunteers is different than the leadership needs of those who regularly work with, manage, and train volunteers, such as cooperative extension specialists and county agents (see Hall \& Broyles, 2015). Rather, we are specifically inquiring about volunteers who wish to become better leaders.

In the course of service, volunteers learn and develop, they create new relationships, and they influence others as their activities augment the potential for social change (Brennan, 2007; Duguid, Slade, \& Schugurensky, 2006). Service opportunities often expose volunteers to unfamiliar populations and conditions of life that may significantly change their self-perception and outlook on the world. Without the capacity for self-reflection and awareness a volunteer might have difficulty functioning in the presence of real or perceived threats to the status quo, such as might be encountered at a food kitchen or in a hospital ward. The willingness to try new things, the commitment to service, and the self-awareness that comes from reflecting on one's service can be both precursors and outcomes of striving to make one's neighborhood or community a better place to live. Shifts in a volunteer's reference frames may bring new assumptions and points of view, broader perspectives, and more inclusive horizons of community involvement (Ilsley, 1990; Ross-Gordon, 2003). Transformations of personal perspective can enhance the value of a volunteer's time in building relationships, deepening the commitment to social action, seeking greater involvement in local issues and expanding the capacity for engagement, creativity, and civic entrepreneurship (Goldsmith, 2010; Meijs \& Brudney, 2007; Mezirow, 1981). Simply said, the qualities that characterize volunteers serving in such a context are also qualities of leaders (Reave, 2005).

Many organizations both encourage the development of leadership among their volunteers and celebrate increases in productivity when volunteers take a proactive role. On the other hand, it may also be true that productivity is lost if supervisors of volunteers are not aware of volunteers' leadership intentions or the factors affecting those intentions. Provision of both task-driven and personal support is essential in the volunteer context, and encouragement of leadership development may be enhanced by understanding influences upon leadershipintention. 
Volunteer Learning and Leadership. Volunteers learn in at least four domains: instrumental skills pertinent to the volunteer setting, skills in working with other people, awareness of volunteers' role in society (Mündel \& Schugurensky, 2008), and knowledge of the self-gained from personal reflection on the volunteer experience (Fisher \& Cole, 1993). Through such learning volunteers often experience growth in their confidence, their ability to create constructive relationships, and their capacity for new levels of accountability. Learning positively affects self-efficacy (Goleman, 1995), job performance (Reio \& Wiswell, 2000) and sense of oneself as a leader (Drucker, 1989, 1990), while reflection on experience has been noted as a powerful tool for building self-awareness (Goleman, 1995), and for linking learning to selfdevelopment and leadership enhancement in a volunteer setting (Mündel \& Schugurensky, 2008; Romero \& Minkler, 2005; Wituk et al., 2003).

Enhanced leadership capacity in the volunteer workforce benefits the agencies as well as the individual volunteers: focusing on building volunteers' strengths has been cited by nonprofit leaders as having the greatest impact on smooth operation of their organizations (Jäger et al., 2009). Organizations that purposefully recognize their volunteers' leadership skills generate positive consequences not only for themselves and their volunteers, but also for the clients and the communities they serve (Fisher \& Cole, 1993; Lulewicz, 1995; Wilson \& Musick, 2000; VanWinkle et al., 2002; Romero \& Minkler, 2005; Brennan, 2007; Snyder \& Omoto, 2008).

\section{Purpose of the Study}

The purpose of this study was to create an instrument, the VLDQ, which may identify the factors affecting intentions of volunteers to express and develop their leadership. TPB (Ajzen, 1991) provided a framework to determine expected predictors of volunteers' intentions to develop their leadership via attitudes, subjective norms, and perceived behavioral control of leadership development. The study addressed the two questions:

1. What are the most salient factors influencing intentions of volunteers to develop their leadership?

2. Can a valid and reliable quantitative instrument be created to discern the intention to develop leadership among volunteers based upon these factors?

To address these questions, we sought to collect data in two phases: first an elicitation study to collect qualitative data for the purpose of developing items for the VLDQ, and second, a pilot study of the VLDQ. Once salient factors influencing volunteers' intentions to developtheir leadership could be identified, an instrument could be developed and tested to determine its ability to identify those $\mathrm{HON}$ volunteers intending to enhance or improve their skills in, knowledge of, and capacity for, leadership. What motivates people to volunteer has been a rich area of inquiry; however, few have endeavored to discover specifically what behavioral and attitudinal factors influence volunteers' intentions to develop their leadership. The term, volunteer leadership, as used in the literature generally refers either to people serving in a voluntary capacity as nonprofit agency board members or advisors; or to individuals in paid staff positions who supervise volunteers. Rather, volunteer leadership, as used in this study refers to 
the full spectrum of volunteers who lend their occasional services to a variety of nonprofit organizations over irregular periods of time, and who wish to develop their skills, knowledge and abilities at any level. Individuals who seek such challenges attract the attention of agency supervisors, who focus on supporting those volunteers to further develop theirleadership.

\section{Theoretical Framework}

The TPB posits that beliefs about a behavior, including the expected outcomes of the behavior and assessments of those outcomes (behavioral beliefs), give rise to positive or negative attitudes regarding the behavior. Beliefs about how others expect us to behave (normative beliefs) generate perceptions of social pressure that influence our motivation to act in accordance with others' expectations. Beliefs about our ability to perform a behavior (control beliefs) influence our perceptions of behavioral control. The TPB also suggests that the indirect measures of behavioral, normative and control beliefs are associated with their respective direct measures (Ajzen, 1991, 2005). A schematic representation of the TPB is given in Figure 1 (Ajzen, 2005).

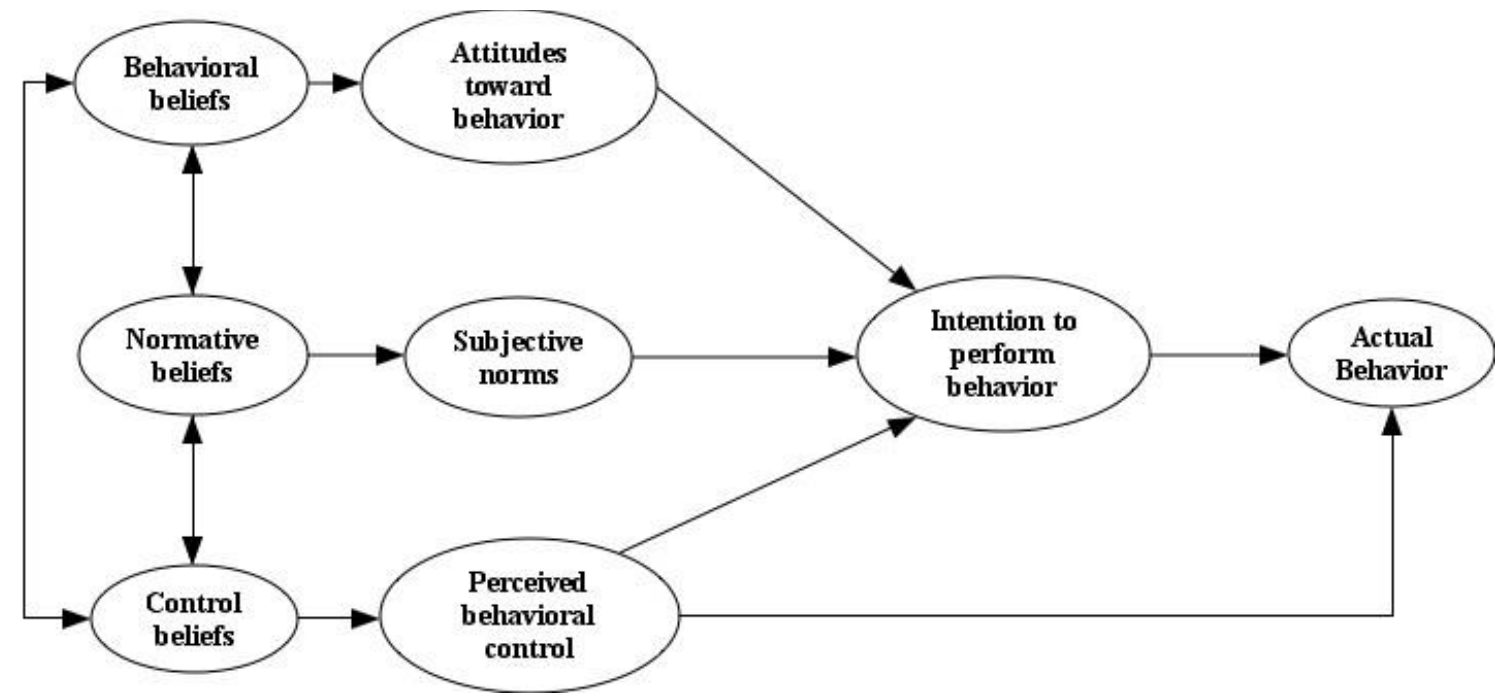

Figure 1. Schematic representation of the Theory of Planned Behavior (Ajzen, 2005).

We assumed that volunteers' attitudes towards leadership development are a function of behavioral beliefs about the consequences of developing or not developing leadership, as well as evaluation of supposed outcomes of developing leadership (Ajzen, 1991). Normative beliefs pertain to perceived expectations of important persons or groups in the volunteer's life, such as family and fellow volunteers. Normative beliefs, combined with volunteers' motivation to develop their leadership, establish the subjective norm regarding leadership development. We also assumed that the perceived capacity of each control factor to hinder or support leadership development behavior contributes to perceived behavioral control in direct correlation with the volunteer's perceived ease or difficulty of developing their leadership (Ajzen, 1991). 
Defining Intention to Develop Leadership. This study did not seek to perceive, define, or measure behaviors resulting from the intention, but rather measure the strength of factors influencing the intention. Per Francis et al. (2004, p. 8):

Although there is not a perfect relationship between behavioural intention and actual behaviour, intention can be used as a proximal measure of behaviour. This observation was one of the most important contributions of the TPB model in comparison with previous models of the attitude-behaviour relationship. Thus, the variables in this model can be used to determine the effectiveness of implementation interventions even if there is not a readily available measure of actual behaviour.

The aim in developing the VLDQ was to provide individuals and agencies with a means of quantifying the intentions of volunteers to develop their leadership skills, regardless of how those intentions or how their leadership abilities might manifest in their work or their lives. Because the intention to develop leadership was self-directed, the self was regarded as the Target in this study. Leadership development was the behavior being investigated and the behavior of which self was the object; therefore, leadership development was considered here to be the Action. Theoretically it is possible for any human being to have the desire, motivation, and intention to develop their capacity for, skills in, and knowledge of leadership, but this study was specifically focused on the volunteer workforce, and volunteering was therefore considered to be the Context. Intention is, by definition, an attitude directed toward the future; however, it was not within the scope of this study to ask respondents to measure their intention in terms of chronology. The time element was therefore assumed to be an undefined future during which the respondent would participate in community service activities as an episodic volunteer.

\section{Methods}

We collaborated with HON to acquire samples for all collection of data in development of the VLDQ. HON annually supports 2.6 million volunteers to conduct 236 thousand projects, logging 25.1 million service hours valued at approximately \$579 million (HandsOn Network, 2013a). Encouragement of leadership development among its volunteers is fundamental to HON's organizational culture. The (paid staff) Volunteer Coordinator at each HON Action Center is provided with materials, guidelines and mentoring to train volunteers who want tolead community service projects. HON also offers online access to a plethora of leadership tools for use by volunteers, including instruction in project management, worksheets, checklists, sample meeting agendas, timelines, a project evaluation survey, and more (HandsOn Network, 2013b).

The Elicitation Study. Participants in the elicitation study included volunteers from six randomly selected HON affiliates representing the Pacific Northwest, Midwest, North, South, Southeast and Northeast regions of the United States. A total of 110 people responded to the elicitation study survey, of which $64(58 \%)$ fully completed the nine qualitative essay questions. Response items were first divided into emergent themes representing the three belief domains. Three researchers independently identified, categorized, and coded all elicitation study responses within the three domains, and counted the number of mentions of each theme. After adding up 
the total number of mentions, each researcher calculated the top $75 \%$ of the most frequently mentioned themes on their respective lists (Francis et al., 2004). Following rigorous data auditing and revisiting of the elicitation study responses, a consensus was reached on the identities and rankings of the themes. These themes are reported as results in Table 1, and formed the basis of developing questionnaire items to pilot test the VLDQ.

The Pilot Study. The questions comprising the pilot VLDQ were developed to assess: intentions to carry out the behavior of developing leadership, attitudes towards the behavior of developing leadership, sources of social pressure about developing leadership, and strength of behavioral control beliefs regarding development of leadership. Because behavioral, normative and control beliefs are psychological constructs, they may be measured either by questioning subjects about their general attitudes (i.e., direct measures), or about particular beliefs and outcome evaluations (i.e., indirect measures), or both. Since different assumptions underlie the direct vs. indirect measurement methods, inclusion of both measurement types makes survey results more robust; using two measurement procedures to address the same construct should yield positively correlated scores. The indirect measures were created in pairs, with each theme extracted from the elicitation study represented in the pilot instrument by one indirect measure to capture the belief about each behavior, and one indirect measure to evaluate the outcome of the behavior. A seven-point response scale for each item was used throughout theinstrument.

We administered the pilot test of the VLDQ through the Qualtrics ${ }^{\text {TM }}$ web-based survey service to more than 4,000 HON volunteers throughout the United States. A total of 655 people responded to the survey, of which 411 responded to every question. Because the number of respondents in the pilot study represented less than $16 \%$ of the target sample, there remains a chance of respondent bias placing limits of generalizability to the targetpopulation.

Pilot Study Data Analysis. We used principal components analysis (PCA) to examine the quantitative data and identify factors associated with volunteers' intentions to develop their leadership. We expected that some distinctions among factors would be based upon the TPB constructs and sub-constructs represented by the survey items in each of the belief domains. We chose orthogonal rotation using Varimax to maximize simplification of the columns in the factor matrix, thereby yielding the clearest possible separation of factors according to the underlying theoretical constructs. PCA allowed examination of relationships underlying the large numbers of variables in the pilot instrument (Tabachnick \& Fidell, 2001). Calculation of Cronbach's alpha provided reliability estimates for the generalized intention and other direct measures within each belief domain.

\section{Results}

Elicitation Study. The predominantly female, mostly Caucasian elicitation study respondents had a mean age of 35 years, and averaged in the $\$ 40,000-\$ 50,000$ range of annual income. Approximately $70 \%$ of participants had four or more years of higher education. Respondents reported a wide range of behaviors indicating potential leadership development, the most frequent being exhibiting self-motivated action in service to the community outside of HON volunteer projects. 
Qualitative data from the elicitation study indicated participants to behavioral, normative, and control beliefs regarding developing their leadership as volunteers. Table 1 shows the top $75 \%$ of response themes in each belief domain ranked in order by frequency of mentions. Themes are explained subsequently with representations of the data.

\section{Table 1}

Rank Order of Top 75\% of Elicited Behavioral, Normative, and Control Belief Themes

\begin{tabular}{lr} 
Themes & Rank Order \\
\hline Behavioral Beliefs & $1(17.39 \%)$ \\
Serve and help others & $2(15.65 \%)$ \\
Building relationships & $3(13.04 \%)$ \\
New knowledge / skills & $4(12.17 \%)$ \\
Self development & $5(10.43 \%)$ \\
Better community & $6(9.56 \%)$ \\
Management conflicts & $7(7.82 \%)$ \\
Role model & $8(6.97 \%)$ \\
Welcoming diversity & $8(6.97 \%)$ \\
Teamwork & \\
& \\
Normative Beliefs & $1(27.14 \%)$ \\
Employers & $2(18.57 \%)$ \\
Family & $3(12.87 \%)$ \\
Other volunteers & $4(10.00 \%)$ \\
Friends & $5(8.57 \%)$ \\
Church/pastor & $5(8.57 \%)$ \\
Other volunteer agencies & $6(7.14 \%)$ \\
Community members & $6(7.14 \%)$ \\
Volunteer agency staff & \\
Control Beliefs & \\
Opportunities to lead & \\
Lack of alignment, coordination or willingness & $1(17.20 \%)$ \\
Supportive \& congenial environment and colleagues & $1(17.20 \%)$ \\
Clear expectations & $2(15.05 \%)$ \\
Autonomy & $3(12.90 \%)$ \\
Training/leadership skill growth & $4(9.68 \%)$ \\
Opportunities to volunteer & $5(7.53 \%)$ \\
Teamwork & $5(7.53 \%)$ \\
Lack of resources & $5(7.53 \%)$ \\
& $6(5.38 \%)$ \\
\hline
\end{tabular}

Elicitation Study: Behavioral Beliefs. It is a premise of the TPB that attitudes are based upon beliefs regarding behavior. A person's attitude is made up of overall assessments of performing the behavior and of the behavior's potential positive or negative consequences. 
Perceptions of both likelihood and the effects of possible consequences lead to behavioral beliefs that result in a positive or negative attitude regarding that behavior. We asked participants to state perceived advantages and disadvantages associated with developing their leadership as volunteers.

Serve and help others. The opportunity to serve and help others was the theme most frequently mentioned as an advantage of leadership development, expressed as a behavioral belief in $17.39 \%$ of responses. Someone who wants to serve and helpothers desires to affect positive change regarding local issues, and to facilitate making the same opportunity available to other people. Because the nature of HON's work is to serve as a clearinghouse and a facilitator of partnerships, people who find volunteer opportunities through HON may serve in a wide variety of nonprofit settings in a given community. Respondents felt that developing their leadership would enhance their ability to serve others through their volunteer efforts. As stated by one participant, "Developing my leadership allows me to find and fulfill a need in the community I have chosen to live in. I also am able to give back to the community by assisting in developing leadership qualities in others by assisting in their education."

Building relationships. Subjects cited the opportunity to expand and solidify their social networks as a behavioral belief in $15.65 \%$ of responses. Responses included comments such as, "I get to meet people that I otherwise wouldn't know. They share the same interest as me and I develop some of the best relationships with these people." One HON affiliate that collected data on the methods by which volunteers learned about the agency found that $25 \%$ of volunteers came to the Action Center through word-of-mouth, or by the invitation of a friend or co-worker (A. Lamb, personal communication, July 14, 2009), a finding that substantiates the connection between volunteer participation and the importance of social networks.

New knowledge/skills. More than $10 \%$ of stated behavioral beliefs fell within the theme of obtaining new knowledge and/or skills as an advantage of volunteer leadership development. Developing one's leadership is perceived by subjects as a way to obtain new information, new competencies, and new levels of understanding. One respondent wrote, "One of the advantages of developing my leadership is that I can use what I learned while helping others in other aspects of my life. Another advantage is that I practice taking the initiative, which is a valuable skill."

Self-development. Responses made it clear that the process of developing one's volunteer leadership expands self-awareness, increases self-confidence, enhances the ability to appreciate others' points of view, and increases responsibility for one's actions. Subjects mentioned empowerment, motivation, maturity, accountability, independence, challenge and self-efficacy in the context of self-development, for example: "The advantages of developing one's leadership is it makes you a more aware person and accountable for your (own) as well as the actions of others. It makes you a more wellrounded person with the experiences that are gained." 
Better community. Study participants sensed that the benefits of personal leadership development reach far beyond the individual, and $10.43 \%$ of them specifically cited a heightened capacity to affect change for the better in theircommunities. Statements like, "By further developing leadership skills, we can support our great city" demonstrated subjects' awareness of the broader impacts of self-development.

Management conflicts. Responses indicated that development of leadership is thwarted when nonprofit organizations are not equipped to appropriately manage and support volunteer leaders. Specific factors mentioned as contributing to management conflicts included poor planning of projects and events, disorganization at project sites, ethical conflicts, the perception that staff felt threatened by volunteers, insufficient opportunities to take on leadership roles or to try new ways of working, and volunteers feeling condescended to by staff or by more senior volunteers. One subject said, "I can see that development of leadership could potentially foster some insecurity andjealousy with an organization's management if not tempered with diplomacy and discretion," while others stated, "(Volunteer) Leaders can be bossy and not unite the group," and, "I felt like I was condescended to as a volunteer (and) not allowed to explore my own creativity in helping the community."

Role model. In statements such as, "It helps to bring more people to volunteer when I can show how gratifying serving my community is, which in turn helps develop leadership," subjects expressed a strong awareness of and commitment to their responsibility as role models. Responses of these volunteers evidenced their attention to providing a positive example for others, particularly children and other volunteers.

Welcoming diversity. Several respondents mentioned the opportunity to interact with people from different cultural settings as an advantage of developing leadership. One subject said, "The advantages of developing leadership when I volunteer are diverse with me learning to communicate and operate with individuals of different races as well as cultural and ethnic backgrounds." Subjects indicated their awareness and appreciation of developing their leadership as an opportunity to work with diverse volunteer and client populations.

Teamwork. Subjects expressed their appreciation of the ability and commitment to work collaboratively with others as a vehicle for developing their leadership. "I believe," wrote one person, "that only by working with others, even though it may not be something that is easy for you, is the only way to truly develop leadership."

Elicitation Study: Normative Beliefs. Every individual is subject to the influence of others' opinions, particularly the opinions of people who are significant. Subjective norms are comprised of beliefs about how others, who might be important to the subject in some way, would want them to behave, along with that person's negative or positivejudgments about those beliefs. We asked participants to identify people in their lives who would approve or disapprove of developing their leadership as volunteers. 
Approval by groups or individuals. The largest category of approving referents, cited by $22.14 \%$ of subjects, was that of employers/supervisors/bosses. Family was the second ranked category, followed by fellow volunteers, friends, and pastors and/or faith community members. Subjects cited volunteer agencies other than HON Action Centers among those they thought would approve of their leadership development, as well as members of the community at large and staff members of the organization(s) for which they currently or might in the future offer their volunteer services.

\section{Elicitation Study Results: Control Beliefs}

Control beliefs address the ability of situational or internal factors to facilitate or inhibit one's performance of a behavior. The extent to which an individual feels able to carry out the behavior depends upon how much control one has over the behavior, and the confidence in one's ability to perform the behavior. We asked participants to identify factors that assist or impede their ability to develop their leadership as volunteers.

Opportunities to lead. The data indicated that volunteers who are regularly given chances to take risks, oversee projects, make decisions, give input, generate solutions and supervise others were better able to develop their leadership. Several respondents cited the lack of such opportunities as a source of frustration. For example, one respondent felt inhibited from leadership development by, "No clear opportunities to volunteer for leadership positions--one-size-fits-all volunteering."

Lack of alignment, coordination, or willingness. Leadership development may be thwarted when agency staff and/or volunteers are mismanaged, poorly organized, or lacking commitment. Participants provided evidence of this in their responses, with examples including, "If everyone around you isn't there to listen, but to do things their own way," "Not having enough work for everyone, not having enough resources to do the work, negative people that put others down," "If every task or job is assigned without any input from me," and "If the people were difficult to work with, unfriendly, or lazy and not enthusiastic."

Supportive environment. Another frequently cited factor contributing to volunteers' capacity for leadership development was the presence of a supportive environment and congenial colleagues. Such an environment is characterized by friendly and encouraging volunteer agency staff, efficient and effective communication among volunteers and staff, and an organizational commitment to volunteer empowerment. One respondent stated, "The factors that encourage development of leadership are present in my current volunteer position; respect, good listening skills, trust, and availability to respond to questions when they arise."

Clear expectations. Volunteer duties, processes and accountabilities need to be well defined. Examples of responses supporting this interpretation include, "Being given a concrete task, position, or job description so that I know what my duties are and the bounds of my responsibility," "Well defined projects with a definite scope and time limit are best," and, "When someone knows what they are supposed to do, then they are trusted 
to do the job without interference, confidence develops. When someone is confident in the job they do, they are confident training another to do it. That is the beginning of leadership."

Autonomy. These volunteers indicated that development of leadership requires being allowed to practice leadership skills, make mistakes, and learn from the leadership experience without being micromanaged. Respondents expressed feeling inhibited from practicing leadership with statements like, "The environment was very overbearing. I felt like I was not being treated as a capable adult and I feel that stifled my ability to thrive and truly enjoy the experience," and, "Management that does not trust me to do my job. Management that micromanages. Management that does not foster open communication, and exchange of ideas."

Training / leadership skill development. Volunteers were better able to develop their leadership when provided with guidance and instruction on how to doso. Respondents cited training and mentoring opportunities, direct contact with trained volunteer leaders, and access to a variety of volunteer tasks and responsibilities. One respondent stated, "...training and seminars to enhance leadership skills," while another specified, "Skill development in areas where I normally don't work on a daily basis."

Opportunities to volunteer. Leadership development may be more likely observed in rapid and efficient organizations that offer individuals numerous occasions for volunteer service. For example, one person stated quite succinctly, "To develop my leadership I should volunteer more often."

Teamwork. Respondents recognized that volunteers were better able to develop their leadership when working cooperatively in a group, as illustrated by the comment, "For me, I like to take charge on my own... However, leadership is mostly about being in a team. In this case, being placed as a leader or part of a team is the best way to develop leadership skills."

Lack of Resources. It is evident that volunteers require information, time, training, recognition, oversight, materials and supplies, and all the other resources necessary to accomplish their goals and develop their leadership. For example, a volunteer responding to the questionnaire wrote, "Not having sufficient information regarding projects and the needs of the projects is challenging at times."

Pilot Study. The predominantly female (76\%), mostly Caucasian (72\%) pilot study respondents had a mean age of 44 years and averaged in the $\$ 60,000-\$ 70,000$ range of annual income. Nearly $70 \%$ of participants had four or more years of higher education. Respondents reported a wide range of behaviors indicating potential leadership development, the most frequent being exhibiting self-motivated action in service to the community outside of HON volunteer projects.

The PCA of the items occurred in two iterations. The initial PCA yielded five factors, 
which is presented in Table 2 . The five rotated factors accounted for $48.689 \%$ of the cumulative variance, and measures of sampling adequacy were found to meet the criteria of .50 as identified by Hair et al. (1998). The Kaiser-Meyer-Olkin measure of sampling adequacy for these 52 variables was .919, and the Bartlett's test of sphericity was 10713.444 with significance of .000 .

\section{Table 2}

Initial Principal Component Analysis of All VLDQ Indirect Measures. Highest load values are bolded and cross-loaded values are italicized.

\begin{tabular}{|c|c|c|c|c|c|}
\hline \multirow[b]{2}{*}{ VLDQ Item } & \multicolumn{5}{|c|}{ Factor Loadings } \\
\hline & $1^{\mathrm{a}}$ & $2^{\mathrm{b}}$ & $3^{\mathrm{c}}$ & $4^{\mathrm{d}}$ & $5^{\mathrm{e}}$ \\
\hline \multicolumn{6}{|l|}{ Other [] volunteers would see developing my leadership } \\
\hline & .729 & -- & -- & -- & -- \\
\hline If I develop my leadership as a [] volunteer, I will be a & & & & & \\
\hline better role model for others. & .701 & -- & .389 & -- & -- \\
\hline $\begin{array}{l}\text { My friends think that developing my leadership as a [] } \\
\text { volunteer is }\end{array}$ & 696 & -- & -- & -- & -- \\
\hline [] staff members think that developing my leadership as & & & & & \\
\hline a volunteer is __. & .679 & -- & -- & -- & -- \\
\hline If I develop my leadership as a [] volunteer, I will help & & & & & \\
\hline $\begin{array}{l}\text { make my community a better place. } \\
\text { If I develop my leadership as a [] volunteer, I will build }\end{array}$ & .673 & -- & .431 & -- & -- \\
\hline my network of relationships. & .672 & -- & .344 & -- & -- \\
\hline My family views my developing my leadership as a [] & & & & & \\
\hline volunteer to be & .656 & -- & -- & .338 & -- \\
\hline If I develop my leadership as a [] volunteer, I will & 656 & 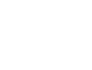 & & 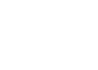 & 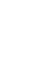 \\
\hline $\begin{array}{l}\text { become more selt-aware. } \\
\text { Members of my community would believe that }\end{array}$ & .656 & -- & -- & -- & -- \\
\hline developing my leadership as a [] volunteer is & .646 & -- & -- & .305 & -- \\
\hline My leadership development will be enhanced if I work & & & & & 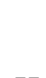 \\
\hline $\begin{array}{l}\text { as a member of a [] team. } \\
\text { If I develop my leadership as a [] volunteer, I will }\end{array}$ & 643 & -- & -- & -- & -- \\
\hline acquire new skills. & .636 & -- & .324 & -- & -- \\
\hline Employers think that developing my leadership as a [] & & & & & \\
\hline volunteer is - . & .617 & -- & -- & -- & -- \\
\hline enhance my ability to serve others. & .585 & -- & -- & -- & -- \\
\hline $\begin{array}{l}\text { Faith community members would consider developing } \\
\text { my leadership as a [] volunteer to be }\end{array}$ & .557 & -- & -- & .313 & -- \\
\hline Volunteer agencies other than [] would regard & & & & & \\
\hline developing my leadership to be ___ & .533 & -- & -- & -- & -- \\
\hline Volunteering as a member of a $\overline{[] \text { team is }}$. & .434 & -- & -- & -- & -- \\
\hline If I develop my leadership as a [] volunteer, I will & $\mathbf{4 3 4}$ & - & 361 & - & 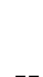 \\
\hline $\begin{array}{l}\text { interact with people of diverse backgrounds } \\
\text { [] volunteers lack adequate organizational resources to }\end{array}$ & .454 & & & -- & -- \\
\hline develop their leadership. & -- & .803 & -- & -- & -- \\
\hline
\end{tabular}


[] volunteers lack instruction on how to develop their leadership.

\begin{tabular}{|c|c|c|c|}
\hline -- & .773 & -- & -- \\
\hline -- & .758 & -- & -- \\
\hline -- & .682 & -- & -- \\
\hline -- & .662 & -- & -- \\
\hline -- & 638 & -- & -- \\
\hline -- & .631 & -- & -- \\
\hline-.340 & .565 & -- & -- \\
\hline-- & .521 & -- & -- \\
\hline -- & -- & .751 & -- \\
\hline -- & -- & .732 & -- \\
\hline -- & -- & .725 & -- \\
\hline-- & -- & .644 & -- \\
\hline .345 & -- & .610 & -- \\
\hline .361 & -- & .567 & -- \\
\hline-- & -- & .479 & -- \\
\hline .413 & -- & .426 & -- \\
\hline -- & -- & -- & .703 \\
\hline .300 & -- & -- & .701 \\
\hline-- & -- & -- & .654 \\
\hline -- & -- & -- & .617 \\
\hline -- & -- & -- & .604 \\
\hline
\end{tabular}

[]'s staff and volunteers are inconsistent in their

commitment to volunteers' success.

Unreliable staff members at [] hinder volunteers'

leadership development.

[] volunteers lack opportunities to work collaboratively in teams.

Expectations are too vague for [] volunteers to perform their duties effectively.

Supervisors oversee [] volunteers in a way that inhibits volunteers from practicing leadership

[] volunteers lack opportunities to oversee projects

There are insufficient opportunities to volunteer with [].

Being able to better serve others is

Increasing my exposure to people of diverse

backgrounds is

Making my community a better place is

Being a good role model to others is

Acquiring new skills is

Becoming more self-aware is

Volunteering within a well organized management

system is

Building a network of relationships is

My friends' approval of my [] volunteer activity is

to me.

Community members' approval of my [] volunteer activity is_to me.

How other volunteer agencies regard me is

Employers' approval of what I do is to me.

The opinion of other [] volunteers is to me.

What my family thinks of what I do with [] is to me.

The approval of [] staff members is to me

What faith community members believe I should do is to me.

If []'s expectations are not clearly defined, developing my leadership is

When support from []'s staff members is inconsistent, developing my leadership is

When I have fewer opportunities to volunteer with[], developing my leadership is

When I do not receive guidance as a [] volunteer, developing my leadership is

When I do not have access to []'s organizational resources, developing my leadership is When I am restrained from using my skills in action 
(including making mistakes), developing my leadership

within [] is

If []'s' commitment to my success is unreliable,

developing my leadership is

If I work independently, rather than with a [] team,

developing my leadership is

Ineffective management makes it difficult to develop my

leadership as a volunteer.

Extraction Method: Principal Component Analysis.

Rotation Method: Varimax with Kaiser Normalization.

${ }^{\text {a }}$ Factor \#1 explained $15.907 \%$ of variance.

${ }^{\mathrm{b}}$ Factor \#2 explained $8.804 \%$ of variance.

${ }^{\mathrm{c}}$ Factor \#3 explained $8.764 \%$ of variance.

${ }^{\mathrm{d}}$ Factor \#4 explained $7.820 \%$ of variance.

${ }^{\mathrm{e}}$ Factor \#5 explained $7.394 \%$ of variance.

Because the first factor in the initial PCA showed a high number and unusual distribution of cross-loaded values, a second PCA was conducted on this factor alone. The second PCA yielded two sub-factors (Table 3). Ultimately, PCA therefore yielded six factors that cumulatively explained $48.69 \%$ of variance and demonstrated virtually exact coherence to the six sub-constructs in the behavioral, normative, and control beliefdomains. 
Table 3. Secondary Principal Component Analysis of Factor \#1 From Initial Principal Component Analysis of Volunteer Leadership Development Questionnaire Indirect Measures. Highest load values are bolded and cross-loaded values are italicized.

\begin{tabular}{|c|c|c|}
\hline \multirow[b]{2}{*}{ VLDQ ITEM } & \multicolumn{2}{|c|}{ Factor Loadings } \\
\hline & $\mathbf{1 A a}$ & $\mathbf{1 B b}$ \\
\hline [] staff members think that developing my leadership as a volunteer is & .738 & -- \\
\hline My family views my developing my leadership as a [] volunteer to be & .727 & .319 \\
\hline My friends think that developing my leadership as a [] volunteer is & .721 & .342 \\
\hline $\begin{array}{l}\text { Members of my community would believe that developing my } \\
\text { leadership as a [] volunteer is }\end{array}$ & .713 & .380 \\
\hline Other [] volunteers would see developing my leadership as___. & .713 & .363 \\
\hline $\begin{array}{l}\text { Faith community members would consider developing my leadership } \\
\text { as a [] volunteer to be }\end{array}$ & .664 & -- \\
\hline Employers think that developing my leadership as a [] volunteer is & .635 & .346 \\
\hline $\begin{array}{l}\text { Volunteer agencies other than [] would regard developing my } \\
\text { leadership to be }\end{array}$ & .483 & -- \\
\hline $\begin{array}{l}\text { If I develop my leadership as a [] volunteer, I will become more self- } \\
\text { aware. }\end{array}$ & .314 & .767 \\
\hline $\begin{array}{l}\text { If I develop my leadership as a [] volunteer, I will interact with people } \\
\text { of diverse backgrounds. }\end{array}$ & -- & .753 \\
\hline $\begin{array}{l}\text { If I develop my leadership as a [] volunteer, I will build my network of } \\
\text { relationships. }\end{array}$ & .362 & .717 \\
\hline $\begin{array}{l}\text { If I develop my leadership as a [] volunteer, I will help makemy } \\
\text { community a better place. }\end{array}$ & .436 & .715 \\
\hline $\begin{array}{l}\text { My leadership development will be enhanced if I work as a member of } \\
\text { a [] team. }\end{array}$ & .400 & .680 \\
\hline $\begin{array}{l}\text { If I develop my leadership as a [] volunteer, I will be a better role } \\
\text { model for others. }\end{array}$ & .518 & .662 \\
\hline If I develop my leadership as a [] volunteer, I will acquire new skills. & .456 & .649 \\
\hline $\begin{array}{l}\text { If I develop my leadership as a [] volunteer, I will enhance my ability } \\
\text { to serve others. }\end{array}$ & -- & .590 \\
\hline Volunteering as a member of a [] team is & .346 & .426 \\
\hline
\end{tabular}

Extraction Method: Principal Component Analysis.

Rotation Method: Varimax with Kaiser Normalization.

a Factor \#1A explained $29.182 \%$ of the variance.

b Factor \#1B explained $57.569 \%$ of the variance.

Factor \#1 contained all eight items in the Subjective Norm: Normative belief subconstruct; Factor \#2 held all eight items in the Behavioral Belief sub-construct; Factor \#3 contained all nine items from the Control Belief: Strength sub-construct; Factor \#4 contained all eight items from the Behavioral Belief: Outcome Evaluation sub-construct; Factor \#5 contained 
all eight items from the Subjective Norm: Motivation to Comply sub-construct; and Factor \#6 contained all nine items from the Control Belief: Power sub-construct.

Cronbach's coefficient alpha was utilized to estimate the internal consistency of generalized intention measures and direct measures in each of the four constructs as follows: generalized intention $(\alpha=.903)$, behavioral belief direct measures $(\alpha=.911)$, normative belief direct measures $(\alpha=.572)$, and control belief direct measures $(\alpha=.551)$. Unfortunately, normative belief and control belief measures were lower than an acceptable .70 reliability coefficient (Schmitt, 1996).

Finally, the mean scores and standard deviations for all 66 direct and indirect items demonstrated a highly restricted range of measurement. The mean of the combined 66 items was 5.34 and the overall standard deviation was 1.25; for 19 (29\%) of the 66 questions only one standard deviation from the mean would take a score beyond the end of the scale. While this deviation from normality was not extreme enough to prevent convergence in the PCA, it nevertheless detracted from the psychometric quality of the instrument.

\section{Conclusion and Recommendations for Future Research}

Until now, researchers had yet to use the TPB to examine the intentions of volunteers to develop their leadership. This study has also brought a new dimension to existing knowledge on use of the TPB by building on previous research with regard to volunteer motivation (Grano et al., 2008; Greenslade \& White, 2005; Warburton \& Terry, 2000). More research is needed to determine if the VLDQ continues to show evidence of strong internal consistency and validity among other volunteer populations, including undergraduate students completing servicelearning projects.

The behavioral belief-based attitude measure yielded the themes: serve and help others, building relationships, new knowledge/skills, self-development, better community, management conflicts, role model, welcoming diversity, and teamwork. These results strongly confirm McCarthy \& Garavan's (2006) findings that emphasized the link between a supportive organizational environment and positive behavioral change. Working as a volunteer can bring a sense of direction and purpose, and an experience of oneself in relationship to one's community that enhances personal development (Drucker, 1990; Wilson \& Musick, 2000). Conversely, when volunteers' understandings, expectations or commitments are not aligned with those of their supervising staff or other volunteers, they feel thwarted in their efforts.

Normative measures showed employers as the group whose approval of leadership development volunteers would most strongly anticipate, thereby affirming Carmeli \& Schaubroeck's (2007) demonstration of the normative influence of authority figures in the workplace. Researchers of volunteerism agree that acknowledgment from the volunteer agency and healthy social interaction with other volunteers are critical to volunteers' wellbeing and ongoing service (Bell et al., 2008; Cowman, Ferarri, \& Liao-Troth, 2004; Farmer \& Fedor, 1999; Gibson, 2009; Lammers, 1991). Important though it is, however, recognition from a host organization constitutes only a very small part of the subjective norm measures as evidencedin 
this study. Numerous studies of volunteer motivation have discussed the value to volunteers of forming supportive relationships with supervisory staff, fellow volunteers and/or volunteer mentors, but few studies of volunteerism or volunteer leadership note the influence on volunteers of social pressures originating outside the host agency.

The belief-based measure of perceived behavioral control educed the themes: supportive environment, opportunities to lead, opportunities to volunteer, teamwork, clear expectations, training/leadership skill growth, lack of alignment/coordination/willingness, lack of resources, and autonomy. These results are consistent with the findings of one study conducted at a HandsOn Action Center (Gibson, 2009), which showed that volunteers whose commitment to service increased over time were more likely to be registered voters, to correspond with newspapers and politicians, and to attend political events. In other words, volunteers who were more highly engaged in a volunteer leadership capacity were also more highly engaged in the civic concerns of their community, thereby demonstrating a high degree of perceived control in corollary community involvement activities. In another study, Perry, Brudney, Coursey and Littlepage (2008) determined that recipients of prestigious volunteer achievement awards were most likely to be highly educated and to be retired, which makes sense since these individuals could be expected to have both fewer family commitments and more free time to volunteer (both pertinent to perceived behavioral control) than other demographic groups. Wituk et al. (2003) also documented outcomes of leadership development that included considerable increases in volunteers' confidence in their ability to make important decisions, to solve problems and to make a difference in their communities, suggesting again the importance of perceived behavioral control as a component of motivation among volunteer leaders.

Volunteering is, at its essence, people offering their services because they want to, and people who exhibit this behavior likely would not do so if they did not think it possible to accomplish the behavior. The obstacles to developing leadership that were voiced by participants in the elicitation study are perhaps the richest source of information offered by this research to volunteer administrators, who wish to empower leadership development in the volunteer workforce. The elicitation study responses that made reference to negative influences on perceived control (e.g., staff and volunteer supervisors who micromanage volunteers; institutional disorganization and inflexibility; lack of clearly defined tasks, roles, orexpectations; insufficient guidance, training and challenge in work assignments) could provide valuable information for alleviating volunteer frustration and burnout.

The results of the pilot study offer only preliminary information to the efficacy of the VLDQ, and the cross-sectional nature of the current research design prevented causal inferences from being made. Our investigation did not identify any particular leading indicators of volunteer intentions to develop leadership. Because our data analyses did not include a path analysis, further research will be required to elucidate the precise nature of interactions among the variables and their effects on volunteer intentions to develop leadership. Future applications of the questionnaire should include analyses of scored instruments to determine whether background variables (both demographic characteristics and volunteer work behaviors)correlate with direct and indirect measures of leadership development intentions. 
The results of this research offer important information for leadership educators, volunteer administrators, cooperative extension agents, as well as companies that want to support or develop corporate volunteer efforts. The behavioral, normative and perceived control beliefs elucidated here, and their pertinence to the development of leadership among volunteers, can provide valuable guidance to those responsible for designing and managing volunteer programs, and for creating work environments in which emergent leaders are recognized, welcomed and encouraged to thrive. Those who work with and those who provide leadership education for volunteers should recognize volunteers' intentions to develop their leadership is dependent on contextual perceptions and attitudes associated with leadership, as well as social pressures in the individual's community. Further, just because someone is able to volunteer may not be reason enough for this individual to intend to develop their leadership as a volunteer, or even continue to volunteer for a particular organization. This said, if we believe as leadership educators in the assumption that all can develop their leadership, the VLDQ may be a useful tool in diagnosing why a volunteer does not intend to develop their leadership. In this situation we may choose to empower the volunteer to develop their leadership by addressing particular behavioral, normative and perceived control beliefs. If we know what drives volunteers to develop their leadership, we may better design leader development programming and training in response to volunteers' leadership intentions.

\section{References}

Ajzen, I. (1991). The theory of planned behavior. Organizational Behavior and Human Decision Processes, 50, 179-211.

Ajzen, I. (2005). Attitudes, Personality and Behavior. New York: Open University Press.

Ajzen, I. (2010a). Behavioral Interventions Based on the Theory of Planned Behavior. Retrieved March 4, 2010, from http://people.umass.edu/aizen/tpb.html

Ajzen, I. (2010b). Sample TPB questionnaire. Retrieved March 4, 2010, from http://people.umass.edu/aizen/tpb.html

Ajzen, I. (2012). Constructing a Theory of Planned Behavior Questionnaire. Retrieved April7, 2012, from http://people.umass.edu/aizen/pdf/tpb.measurement.pdf

Ajzen, I., \& Fishbein, M. (1980). Understanding attitudes and predicting social behavior. Englewood Cliffs, NJ: Prentice-Hall, Inc.

Andenoro, A. C., Allen, S. J., Haber-Curran, P., Jenkins, D. M., Sowcik, M., Dugan, J. P., \& Osteen, L. (2013). National Leadership Education research agenda 2013-2018: Providing strategic direction for the field of leadership education. Retrieved from Association of Leadership Educators website: http://leadershipeducators.org/ResearchAgenda.

Bell, S., M. Marzano, et al. (2008). What counts? Volunteers and their organisations in the recording 
and monitoring of biodiversity. Biodiversity Conservation, 17, 3443-3454.

Brennan, M. (2007). Placing volunteers at the center of community development. The International Journal of Volunteer Administration, 24(4), 5-13.

Carmeli, A., \& Schaubroeck, J. (2007). The influence of leaders' and other referents' normative expectations on individual involvement in creative work. The Leadership Quarterly, 18, 35-48.

Connors, J., \& Swan, B. (2006). A synthesis of leadership development research in agricultural education: 1988-2003. Journal of Agricultural Education, 47(2), 1-13.

Corporation for National and Community Service (2013). Volunteering and Civic Life in America 2012. Retrieved October 24, 2013, from http://www.volunteeringinamerica.gov/

Cowman, S., Ferrari, R, \& Liao-Troth, M. (2004). Mediating effects of social support on firefighters' sense of community and perceptions of care. Journal of Community Psychology, 32(2), 121-126.

Duguid, F., Slade, B., \& Schugurensky, D. (2006, July). Unpaid work, informal learning and volunteer cultures. Paper presented at the $26^{\text {th }}$ Annual SCUTREA Conference, 4-6 July 2006, Trinity and All Saints College, Leeds, UK. Retrieved July 25, 2010, from http://www.leeds.ac.uk/educol/documents/155206.htm.

Drucker, P. (1989, July-August). What business can learn from nonprofits. Harvard Business Review, 88-93.

Drucker, P. (1990). Managing the Non-Profit Organization. New York: HarperCollins.

Farmer, S., \& Fedor, D. (1999). Volunteer participation and withdrawal: A psychological contract perspective on the role of expectations and organizational support. Nonprofit Management \& Leadership, 9(4), 349-367.

Fisher, J., \& Cole, K. (1993). Leadership and Management of Volunteer Programs: A Guidefor Volunteer Administrators. San Francisco: Jossey-Bass.

Francis, J., Eccles, M., Johnston, M., Walker, A., Grimshaw, F., Foy, R., and others (2004). Constructing questionnaires based on the theory of planned behavior: A manual for health service researchers. Retrieved March 4, 2010, from http://people.umass.edu/aizen/tpb.html

Gibson, C. (2009). The leadership ladder: Fostering volunteer engagement and leadership at New York Cares ${ }^{\circledR}$. New York: New York Cares, Inc.

Goldsmith, S. (2010). The Power of Social Innovation. San Francisco: Jossey-Bass.

Goleman, D. (1995). Emotional Intelligence. New York: Bantam Press. 
Grano, C., Lucidi, F., Zelli, A., \& Violani, C. (2008). Motives and determinants of volunteering in older adults: An integrated model. International Journal of Aging and Human Development, 67(4), 305-326.

Greenslade, J., \& White, K. (2005). The prediction of above regular participation in volunteerism: A test of the theory of planned behaviour and the volunteers functions inventory. Journal of Social Psychology, 145(2), 155-172.

Groves, R., Dillman, D., Eltinge, J. \& Little, R. (2002). Survey Nonresponse. New York: John Wiley \& Sons.

Hall, J. L., \& Broyles, T. W. (2015). Leadership competencies of Tennessee extension agents: Implications for professional development, Journal of Leadership Education, 15(3), 187200.

HandsOn Network (2013a). About HandsOn: Our Network. Retrieved July 15, 2013, from http://www.handsonnetwork.org/about/our-network.

HandsOn Network (2013b). Get HandsOn! Volunteer leader toolkit. Retrieved June 14,2010, from http://www.handsonnetwork.org/volunteers/toptools.

Ilsley, P. (1990). New Insights on Strengthening Volunteer Participation, Learning, and Commitment. San Francisco: Jossey-Bass.

Jäger, U., Kreutzer, K., \& Beyes, T. (2009). Balancing acts: NPO-leadership and volunteering. Financial Accountability \& Management, 25(1), 79-97.

Lammers, J. (1991). Attitudes, motives, and demographic predictors of volunteer commitment and service duration. Journal of Social Science Research, 14(3), 125-140.

Lulewicz, S. (1995). Training and Development of Volunteers. In T. D. Connors (Ed.), The Volunteer Management Handbook. Hoboken, M.J.: Wiley.

McCarthy, A., \& Garavan, T. (2006). Postfeedback development perceptions: Applying the theory of planned behavior. Human Resource Development Quarterly, 17(3), 245-267.

Meijs, L., \& Brudney, J. (2007). Winning volunteer scenarios: The soul of a new machine. The International Journal of Volunteer Administration, 24(6), 68-79.

Mezirow, J. (1981). A critical theory of adult learning and education. Adult Education, 32(1), 324. 
Mündel, K., \& Schugurensky, D. (2008). Community based learning and civic engagement: informal learning among adult volunteers in community organizations. New Directions for Adult and Continuing Education, 118, (Summer), 49-60.

Perry, J., Brudney, J., Coursey, D., \& Littlepage, L. (2008). What drives morally committed citizens? A study of the antecedents of public service motivation. Public Administration Review, May-June, $445-458$.

Reave, L. (2005). Spiritual values and practices related to leadership effectiveness. The Leadership Quarterly, 16, 655-687.

Reio, T., Jr., \& Wiswell, A. (2000). Field investigation of the relationship among adult curiosity, workplace learning, and job performance. Human Resource Development Quarterly, $11(1), 5-30$.

Romero, L., \& Minkler, M. (2005). Gold in gray: Senior volunteer leaders as an untapped public health resource. Generations, 29(2), 36-40.

Ross-Gordon, J. (2003). Adult learners in the classroom. New Directions for Student Services, 102,4353.

Snyder, M., \& Omoto, A. (2008). Volunteerism: Social issues perspectives and social policy implications. Social Issues and Policy Review, 2(1), 1-36.

Stedman, N. (2004). Volunteer administration: Theoretical dimensions of the discipline. Journal of Leadership Education, 3(1), 4-16.

Schmitt, N. (1996). Uses and abuses of coefficient alpha. Psychological Assessment, 8(4), 350353.

Tabachnick, B., \& Fidell, L. (2001). Using Multivariate Statistics. Boston: Allyn and Bacon.

VanWinkle, R., Busler, S., Bowman, S., \& Manoogian, M. (2002). Adult volunteer development: Addressing the effectiveness of training new 4-H leaders. Journal of Extension, 40(6), 6FEA4. Retrieved 08/06/10 from http://www.joe.org/joe/2002december/a4.php.

Warburton, J., \& Terry, D. (2000). Volunteer decision making by older people: A test of arevised theory of planned behavior. Basic and Applied Social Psychology, 22(3), 245-257.

Wilson, J., \& Musick, M. (2000). The effects of volunteering on the volunteer. Law and Contemporary Problems, 62(4), 141-168.

Wituk, S., Warren, M., Heiny, P., Clark, M., Power, C., \& Meissen, G. (2003). Developing communities of leaders: Outcomes of a statewide initiative. Journal of Leadership and Organizational Studies, 9(4), 76-86. 


\section{Authors}

Janina M. Fuller, Ph.D., is a coach, speaker, researcher, and workshop leader specializing in leadership development. With over 30 years of experience in the private and nonprofit sectors, she focuses on supporting continuous individual growth, organizational improvement and betterment of the community in the face of diverse challenges. Email:janinawing@gmail.com

Curtis R. Friedel, Ph.D., is an Assistant Professor and Director of the Center for Cooperative Problem Solving in the Department of Agricultural, Leadership, and Community Education at Virginia Tech. His scholarship includes the study of problem-solving teams working together as leaders. Email: cfriedel@vt.edu. 